\title{
A review of remotely sensed satellite image classification
}

\author{
Sakshi Dhingra, Dharminder Kumar \\ Department of Computer Science and Engineering, Guru Jambheshwar University of Science and Technology, India
}

\begin{tabular}{l} 
Article Info \\
\hline Article history: \\
Received Apr 24, 2018 \\
Revised Dec 3, 2018 \\
Accepted Dec 15, 2018 \\
\hline
\end{tabular}

Keywords:

Feature extraction

Remote sensing

Satellite image classification

Supervised classification

Unsupervised classification

\begin{abstract}
Satellite image classification has a vital role for the extraction and analysis of the useful satellite image information. This paper comprises the study of the satellite images classification and Remote Sensing along with a brief overview of the previous studies that are proposed in this field. In this paper, the existing work has been explained utilizing the classification techniques on satellite images of Alwar region in India that covers decent land cover features like Vegetation, Water, Urban, Barren, and Rocky regions. The postimplementation of the classification algorithms, the classified image is obtained displaying different classes that are represented by different colours. Each feature is represented by a different colour and can be easily perceived from the image obtained after classification. The focus of this study is on enhancing the classification accuracy by using proper classifiers along with the novel feature extraction techniques and pre-processing steps. Work of different authors is being discussed in a tabular form defining the methods and outcomes of the respective studies.
\end{abstract}

Copyright $\odot 2019$ Institute of Advanced Engineering and Science. All rights reserved.

\section{Corresponding Author:}

Sakshi Dhingra,

Department of Computer Science and Engineering,

Guru Jambheshwar University of Science and Technology,

Hissar, Haryana-125001, India.

Email: sakshi24.dhingra@gmail.com

\section{INTRODUCTION}

A satellite image can be defined as a representation of complete or earth part acquired with artificial satellites; in which images have number of utilization like cartography, military intellect, and weather prediction [1]. These images could be water vapor images, visible light and infrared images. The visible light image comprises of images portraying the sky as well as the ground demonstration from outer space at a specified time. Water vapour images mainly illustrate the humidity within the environment, usually in cloud form. It could generally be employed for tracking imminent storms with the weather prediction situations.

Satellite image generally encompasses rich contents and plays a significant role in delivering the environmental evidence. Satellite as well as remote sensing images gives quantifiable as well as qualitative evidence which minimize the field effort and the interval complexity. The sensing equipment integrates the data and the images at normal intervals. The data quantity obtained from the data centres is enormous with the exponentially rising like the technology is developing at a quick speed. There is an extreme requirement of a robust technique for the extraction of useful information from the images [2]. The classification has emerged as influential and robust techniques that fulfil the needs for the extraction of important information.

The classification has a significant role in the removal of important information from the satellite images. The classification is usually defined as a procedure of integrating the pixels with the significant classes. This classification process is generally performed with workflow in multi steps [3].

Its classification can also be mentioned as the procedure of mining valuable data from large volumes of the satellite images and its classification is not compound; however, the examiner has to execute multiple options which range in the process of satellite image classification [4]. This includes analysis of spatial data mining, remote sensing images, analyzing varied vegetation kinds like farming, forestry etc. and examining 
urban regions for determining several land usages of the region. In late 1972, Landsat-I was the initial satellite to integrate Earth reflectance on the $60 \mathrm{~m}$ resolution. On that time period, the supervised and unsupervised classifications were taken as two methods and it was enough in case of spatial resolution [5]. With the passage of time, the demand of remotely sense has been increased. Numbers of remote sensing application are there related to environmental, public safety and food security. To fulfil these demands, the satellite images aimed at an enhanced spatial resolution at higher frequency range, though, this doesnassure improved land cover. The usage of image classification techniques is considered as a significant factor for improved accuracy [6]. Figure 1 shows a satellite image which contains varios segments like crop, barren etc.

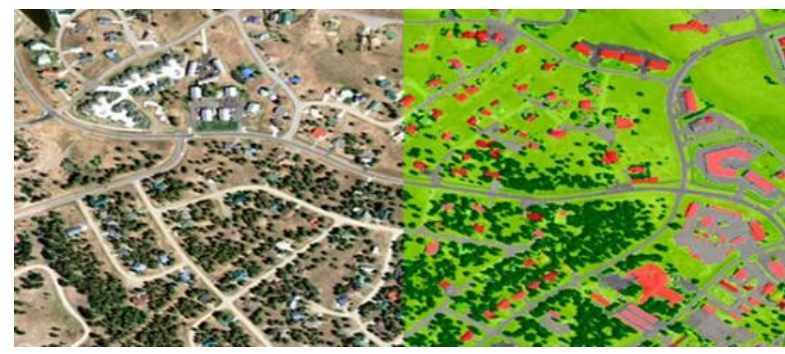

Figure 1. Satellite image including trees, lower vegetation, impervious surfaces and hydrological features

From the historical point of view, the classification accuracy came out to be less due to the lack of appropriate feature extraction and selection algorithm. In satellite image, feature extraction and selection process play a vital role to achieve better accuracy. In the traditional work, there is no existence of such combination (feature extraction and selection) [7]. The existing work is deficient in finding plane according to different frequencies from satellite images. So, it is mandatory to apply pre-processing to find the plane as per frequencies.

The above problem can be solved by using the basic pre-processing steps such as plane extraction, ROI extraction, plane filtering using morphological operations etc. In the post-processing step, hybrid feature selection algorithm like the combination of GA (Genetic Algorithm) with ABC (Artificial bee colony) can be used. With this combination, if the classifier can be used than the outcome would be better.

The manuscript could be organized in the below approach: The first segment deals with introduction of satellite image classification that defines the background of the concept with the narration of the problem following the proposed work that can be adopted to solve the problem. The concept of remote sensing is explained later. After that, the focus has been given to different studies via which the classification of satellite images can be done. Later, the focus has been given to different classifiers through which the classification will be done on the basis of several types of bands that exist in the satellite image. A comparison has been in the on the basis of satellite image and classified satellite image for to detecting the presence of vegetation based on the different scenarios. At the end of this paper, a glance of existing techniques is provided in the tabular form.

\section{REMOTE SENSING}

The data being acquired in the objects within the earth surface lacking in approaching in contact with them is remote sensing. Sensors are devices used for conducting investigations. It claimed that it is feasible for the accumulation of data on risky or isolated regions. Its applications keeps an eye on regions of deforestation like Amazon Basin, climate variation significances in glaciers as well as the Arctic with the Antarctic regions with the pitch coastal sounding with the ocean pitches [8]. Its data has spatial as well as spectral resolutions: Spatial resolution is defined as a computation of shortest pointed or linear parting among two objects which could be determined via a sensor. If the resolution of sensor is more then the capacity of data is greater but smaller area is enclosed. The coverage of field with the resolution is interconnected with the extent for the representation. Spectral resolution is considered as the magnitude with the statistic of precise intervals of wavelength within the electromagnetic spectrum for which a sensor is vulnerable. Due to restricted bandwidths in several domains of the electromagnetic spectrum, numerous features are readily specified. Image spectroscopy or hyper-spectral investigation is the process of scanning numbers of closely arranged and quite linear spectral bands [9-10]. The word hyper-spectral is used to refer the spectra that dwell a large fraction of narrow, short spaced spectral bands. To tackle with the hyperspectral image classification query, many supervised and unsupervised analysis has been approached. 


\subsection{Remote sensing images}

The classification of remote sensing images is into three parts as shown in Table 1 [11].

Table 1. Various Remote Sensing Images

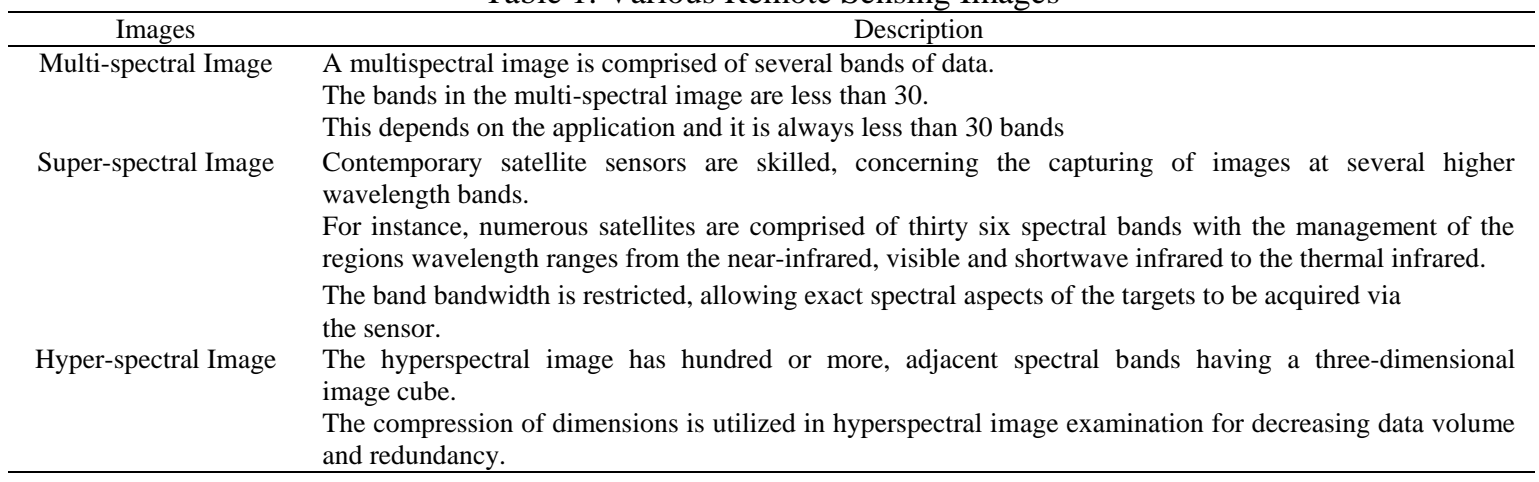

\subsection{Taxonomy of image classification methods}

Image classification is categorized into different categories on the basis of different criteria's [12]. Table 2 is giving an overview of methods on the basis of characteristics with classifiers example.

Table 2. Image Classification Method Taxonomy

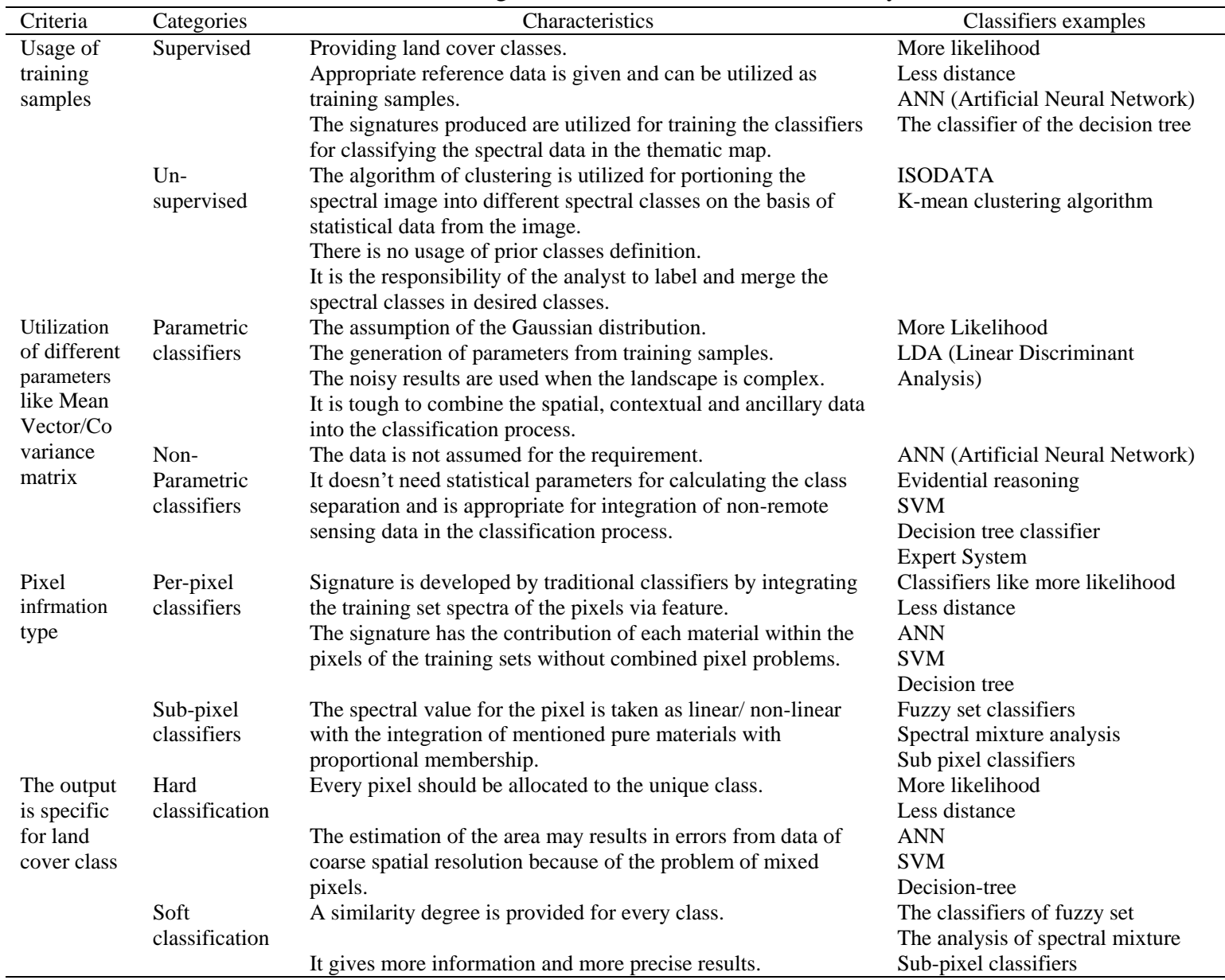


Table 2. Image Classification Method Taxonomy (continue)

\begin{tabular}{|c|c|c|c|}
\hline Criteria & Categories & Characteristics & Classifiers examples \\
\hline \multirow{5}{*}{$\begin{array}{l}\text { Utilization } \\
\text { of spatial } \\
\text { Inform- } \\
\text { ation }\end{array}$} & Spectral & Usage of spectral information in the classification of & More likelihood \\
\hline & classifiers & images. & Less distance \\
\hline & & $\begin{array}{l}\text { Because of high variations in the spectral distribution of } \\
\text { similar class, noisy classification may result }\end{array}$ & ANN \\
\hline & $\begin{array}{l}\text { Contextual } \\
\text { classifiers }\end{array}$ & Usage of spatially neighbouring classification information & $\begin{array}{l}\text { Correction of a point to point } \\
\text { context }\end{array}$ \\
\hline & & & $\begin{array}{l}\text { Classifier of frequency dependent } \\
\text { contextuals }\end{array}$ \\
\hline
\end{tabular}

\section{FEATURE EXTRACTION}

Features are those things which distinctively define an object, such as size, shape, composition, location, etc. [13]. With the effortless availability and advancement in the resolution of satellite images, more study efforts have had been laid in the recent times on extracting features from satellite images. These features primarily comprise structures and facilities (i.e. buildings, flyovers, airports, etc.), land use, land cover, vegetation classification (i.e. agriculture, forestry, environmental, mineral), water bodies, well locations, topsoil varieties, conduits, pipelines and many more [13].

Feature extraction can be defined primarily as an image processing technique which is used to spot and classify mutual relationships or mutual meaning concerning the image areas. Segmentation methods are employed to separate the preferred entity from the image for developing the computation. The feature extraction stage is intended to acquire a compact, non-redundant and significant depiction of interpretations. It is accomplished by eliminating redundant and inappropriate material from the data. These features are then utilized by the classifier in order to classify the data. The classifier that uses concise and appropriate features will deliver more precision and also involves less memory, which is the most anticipated aspect of a real-time system. Besides the increasing precision, the feature extraction procedure also enhances the computational speed of the classifier. There are certain steps that are required to be followed in order to perform the feature extraction from an object as defined below [14].

a. Image pre-processing

b. Image Segmentation

When pre-processing and the favoured segmentation level is created, then the capture strategy feature will be implemented in segments to get features, followed by the implementation of classification and post-processing methods.

In pre-processing the image, the sensors record the image data of the satellite which permits the bugs to have pixel and geometry values. The correction of the bugs is using exact mathematical models which can be a statistical or specific model. The enhancement of images is the amendment of an image by altering the pixel value for the improvement of an image effect. It usually has a number of techniques that enhance the image's visual appearance that would later be considered as better for the machine and human analysis [15].

Occasionally imagery taken from satellites is less in contrast and light due to limits of imaging subsystems with the lighting circumstances with the capturing of the image. The images have varied noises. With the enhancement of some image, the aim is to capture the features of some images for successive review. For instance; edge and contrast enhancement, noise filtering, pseudocoloring and expansion. It is necessary for capturing features like image display and image analysis. The process of enhancement does not enhance the data being inherited. It relies on some image features[16].

Segmentation is known as the main issue in image processing. It is the procedure that generates the image and the objects. The degree according to which the part is based solves the issue means that the segmentation has to be stopped while the objects of interest in some application are separate for instance, With independent use of targeted air-to-ground acquisition, assuming our interest lies in Determining the vehicles on a road, the first step is to segment the road from the image and then segment the contents of the road to possible vehicles. Image thresholding techniques are utilized for image segmentation.

It becomes important to focus on the stage of taking this feature with a striking effect on the effectiveness of the recognition system [17]. The selection of features is a significant factor for achieving recognition of high performance. The extraction of features is "extracting from the raw data information that is most suitable for classification purposes while minimizing the within class pattern variability and enhancing the between-class pattern variability". Therefore, choosing an appropriate approach to getting features according to the input provided. For these factors, it would be important to check varied accessible features for getting features in a specified domain by covering the vast probabilities of the cases. 


\section{CLASSIFICATION METHODS}

There are several approaches and methods that are associated with satellite image classification. But most widely satellite images are classified into two main categories as shown in the Figure 2 i.e. Pixelbased as well as Object-based. The pixel-based techniques are further divided into unsupervised and supervised techniques [18]. A brief about various classification methods are tabulated in the Table 3 .

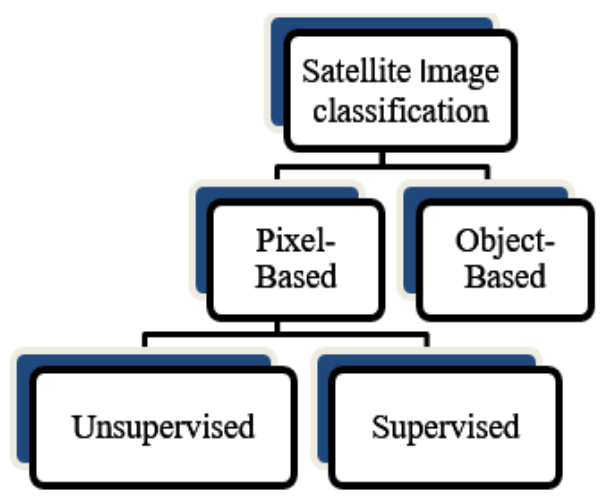

Figure 2. Satellite image classification techniques

Table 3. Classification Methods

\begin{tabular}{|c|c|}
\hline Methods & Description \\
\hline \multirow[t]{5}{*}{$\begin{array}{l}\text { Pixel-based } \\
\text { classification }\end{array}$} & $\begin{array}{l}\text { Pixel-based classifications are based on the grey value of pixels and for the classification purpose only spectral information } \\
\text { is used. }\end{array}$ \\
\hline & These are considered as the least unit that depicts some image. \\
\hline & $\begin{array}{l}\text { This technique utilizes the statistics of reflectance for particular pixels. } \\
\text { It assembles pixels to express land cover features. }\end{array}$ \\
\hline & The land coverage has to be forested, metropolitan, agricultural and another features variety. \\
\hline & $\begin{array}{l}\text { The classification of the pixel is further categorized into unsupervised as well as supervised classification. } \\
\text { In this, pixels are integrated according to the reflectance properties. }\end{array}$ \\
\hline \multirow{7}{*}{$\begin{array}{l}\text { Unsupervised } \\
\text { Classification }\end{array}$} & These groups are individually called as 'Clusters'. \\
\hline & The analyst classifies the varied clusters to produce and the bands to utilize. \\
\hline & The analyst recognizes the clusters with the classes of land coverage classes. \\
\hline & $\begin{array}{l}\text { Later, analyst allocates significant labels to the clusters and delivers properly satellite image. } \\
\text { It is frequently the case in which several clusters stand for a distinct land cover class. }\end{array}$ \\
\hline & The analyst integrates the clusters into a land cover category. \\
\hline & This classification method is usually employed while no sample locations exist. \\
\hline & K-means and ISODATA are the techniques used for unsupervised classification of the satellite images \\
\hline \multirow{7}{*}{$\begin{array}{l}\text { Supervised } \\
\text { Classification }\end{array}$} & In the Supervised classification, an input is required from the analyst. \\
\hline & The input of the analysts is termed as 'training set'. \\
\hline & $\begin{array}{l}\text { The sample of training is considered to be an important aspect of the methods of supervised classification and the accuracy } \\
\text { of these methods vastly on the samples employed for the purpose of training. }\end{array}$ \\
\hline & The classification is based on the spectral signatures in the training set. \\
\hline & Each class is demonstrated on the basis of what it is similar to the most in the sets of training. \\
\hline & Foremost classifiers for supervised classification are Minimum-distance, parallelepiped and maximum likelihood. \\
\hline & The algorithm primarily separates the pixels from each other based on the training samples that denote a site on the ground. \\
\hline \multirow{7}{*}{$\begin{array}{l}\text { Object-Based } \\
\text { Classification }\end{array}$} & It is different from pixel-based classification approach as it works on the group of pixels instead of direct pixels. \\
\hline & $\begin{array}{l}\text { In Object-Based image classification, some image is interpreted not only for single pixel but is also valid in significant } \\
\text { image objects and their common relationships. }\end{array}$ \\
\hline & Object-based information extraction is relies upon spectrum character, geometry as well as structure evidence. \\
\hline & This method offers actually innovative data and can simply accessible. \\
\hline & Object-Based Classification has two main stages: \\
\hline & i. Image Segmentation to generate a segmented image \\
\hline & Classification of the segmented image. \\
\hline
\end{tabular}




\subsection{Supervised classification algorithms}

The following algorithms Table 4 are the types of supervised classification techniques that can be utilized in the research work for the classification of the remotely sensed satellite images.

Table 4. Algorithms of Supervised Classification

\begin{tabular}{|c|c|}
\hline Algorithms & Description \\
\hline Support Vector & It was first introduced by Vapnik in 1979 , based on the principles of statistical learning theory. \\
\hline \multirow[t]{10}{*}{ Machine (SVM) } & $\begin{array}{l}\text { SVMs are a decent and straightforward example of a supervised classification technique for remote sensor } \\
\text { data classification. }\end{array}$ \\
\hline & $\begin{array}{l}\text { It is the major classification method that follows classification tasks with the erection of hyperplanes in } \\
\text { the multidimensional space with the isolate scenarios of varied class labels. }\end{array}$ \\
\hline & $\begin{array}{l}\text { Regression as well as classification tasks and uphold several persistent as well as unconditional SVM } \\
\text { variables. }\end{array}$ \\
\hline & $\begin{array}{l}\text { This technique is suitable for distinguishing the patterns as well as the objects that are utilized for pixel- } \\
\text { based as well as object-based classification. }\end{array}$ \\
\hline & It can be initiated by describing the samples of training. \\
\hline & $\begin{array}{l}\text { The aim of the training is the discovery of some function which defines the relative } b \text { among output as } \\
\text { well as input. }\end{array}$ \\
\hline & $\begin{array}{l}\text { The subsequent is SVM method to find the best extrication hyper-plane between classes by focussing on } \\
\text { the ready data placed at the end of the class descriptors. }\end{array}$ \\
\hline & $\begin{array}{l}\text { The organized data is known as Support Vector which has a vital role in the learning machine role } \\
\text { because they are the training data elements which may vary the hyperplane position if diminishsed. }\end{array}$ \\
\hline & $\begin{array}{l}\text { In this process, the optimal hyperplane is fixed and effectively use fewer preparation data, so the accuracy } \\
\text { of the classification increases with the prepared data set [16]. }\end{array}$ \\
\hline & $\begin{array}{l}\text { This method is most advantageous for remote sensing images and is more accurate than other popular } \\
\text { techniques such as neural network classifiers. }\end{array}$ \\
\hline \multirow{9}{*}{$\begin{array}{l}\text { K-nearest } \\
\text { neighbor } \\
(\mathrm{k}-\mathrm{NN})\end{array}$} & It is a way for classification of entities on the basis of the adjoining training specimens in feature space. \\
\hline & $\begin{array}{l}\text { In this classification, outcome is a considered as class-membership. The object has been classified from } \\
\text { huge vote from nearby neighbors having the entity which is allocated to class mutual between the entities } \\
\text { k-adjoining neighbors. }\end{array}$ \\
\hline & $\begin{array}{l}\text { The prime intention of the } \mathrm{k} \text { Nearest Neighbours }(\mathrm{KNN}) \text { process is to use the database wherein the data } \\
\text { are divided into a number of remote classes to predict the classification of novel sample point. KNN } \\
\text { classification distributes data into a test set and training sets. }\end{array}$ \\
\hline & $\begin{array}{l}\text { Then the K nearest training set objects are originated for every single row of the test set and the processor } \\
\text { task of classification is performed by predominance vote with connections which can be broken at any } \\
\text { moment. }\end{array}$ \\
\hline & The K-nearest neighbor algorithm $(\mathrm{KNN})$ can be summarised primarily as per the following steps: \\
\hline & (i) A positive number $\mathrm{k}$ is stated, with a new sample \\
\hline & (ii) The $\mathrm{k}$ items are selected from the database that is next to the new sample \\
\hline & (iii) The utmost mutual classification of selected entries is determined. \\
\hline & (iv) Resulted Classification is offered to the new sample. \\
\hline \multirow[t]{9}{*}{$\begin{array}{l}\text { Artificial Neural } \\
\text { Network (ANN) }\end{array}$} & $\begin{array}{l}\text { ANN got the rise of popularity as an alternative to statistical methods for Remote Sensing Data } \\
\text { classification. }\end{array}$ \\
\hline & The popularity is dependent on the active nature and fault tolerance. \\
\hline & $\begin{array}{l}\text { The models of ANN are applicable to all types of data, and no mathematical relationship applies to data } \\
\text { and its classes. }\end{array}$ \\
\hline & It generally has three diverse components with I/P layer, hidden-layer with the O/P layer. \\
\hline & $\begin{array}{l}\text { ANN has the one I/P layer, one } \mathrm{O} / \mathrm{P} \text { layer having varied neurons and there is a variation of hidden layer } \\
\text { with the variation of neurons. }\end{array}$ \\
\hline & The neurons of $\mathrm{I} / \mathrm{P}$ to hidden and hidden to $\mathrm{O} / \mathrm{P}$ node are like via weight. \\
\hline & $\begin{array}{l}\text { Initially, the weights are arbitrary but when ANN is trained then each of the weights are accustomed and } \\
\text { accomodate to the data. }\end{array}$ \\
\hline & Basic elements of NN are the processing node corresponding to human brain neurons. \\
\hline & $\begin{array}{l}\text { Each processing node admits and sums a set of input values, and transfers this value through an activation } \\
\text { function with the output value of the node that generates one of the inputs to a node that executes the next } \\
\text { layer of ANNs. }\end{array}$ \\
\hline
\end{tabular}

\section{RELATED WORK}

It is a research field in which the people are working on varied sorting models, feature extraction, dimension reduction, and accuracy. A tabular comparison of the previously carried researchers has been presented in this section of the paper as shown in Table 5. 
Table 5. A Glance at Existing Techniques

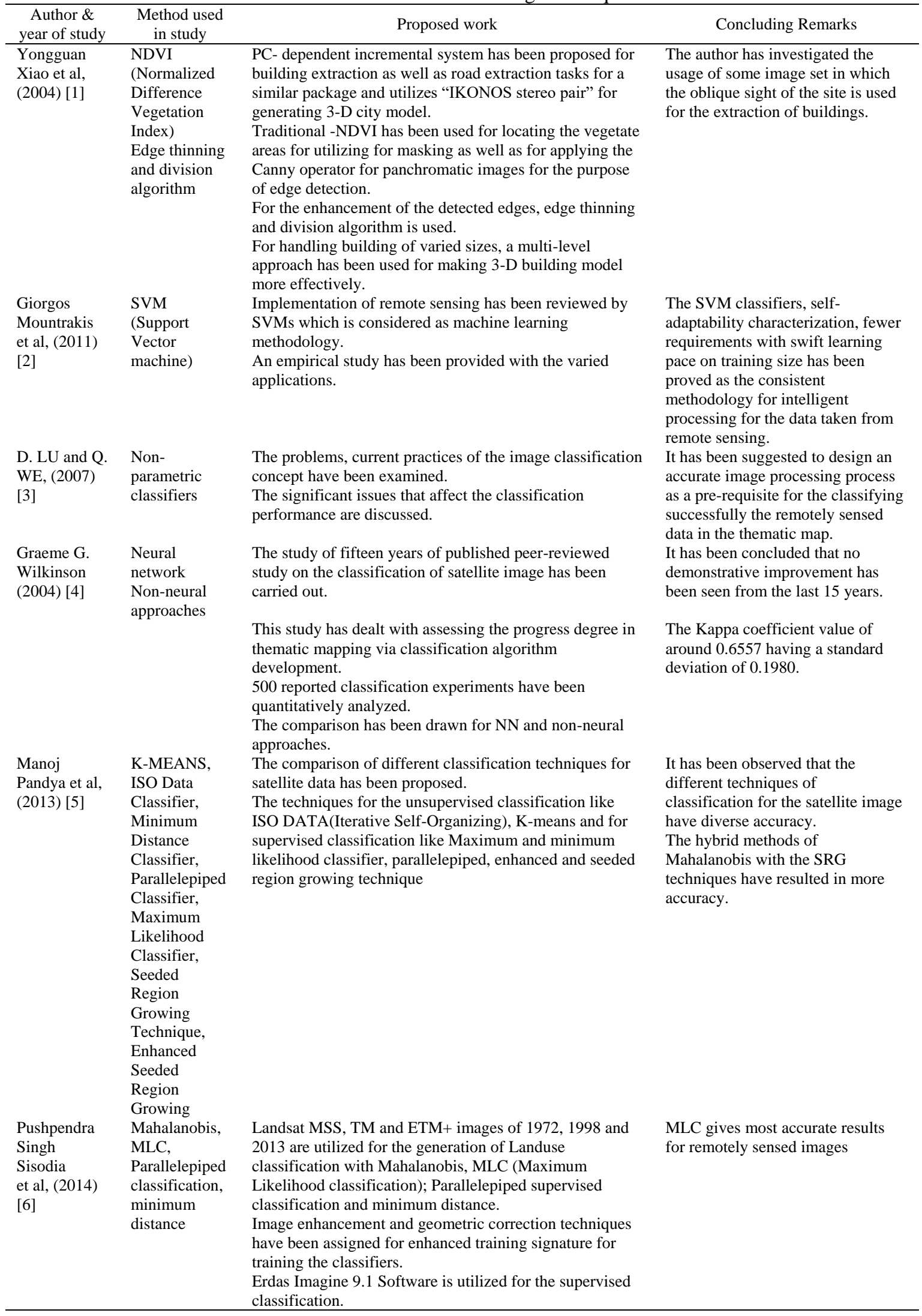


Table 5. A Glance at Existing Techniques (continue)

\begin{tabular}{|c|c|c|}
\hline $\begin{array}{c}\text { Author \& } \\
\text { year of study }\end{array}$ & $\begin{array}{l}\text { Method used } \\
\text { in study }\end{array}$ & Proposed work \\
\hline $\begin{array}{l}\text { NurAnisMah } \\
\text { mon } \\
\text { et al,(2014) } \\
{[7]}\end{array}$ & $\begin{array}{l}\text { ANN } \\
\text { Maximum } \\
\text { Likelihood } \\
\text { (ML) } \\
\text { ISODATA }\end{array}$ & $\begin{array}{l}\text { This research has dealt with the survey of ANN } \\
\text { capability for classifying the satellite image with } \\
\text { different ANN approaches. } \\
\text { A review of different techniques for the satellite image } \\
\text { classification of the satellite images has been compared } \\
\text { with the ANN on the Accuracy basis. }\end{array}$ \\
\hline $\begin{array}{l}\text { Soumadip } \\
\text { Ghosh } \\
\text { et al,(2014) } \\
{[8]}\end{array}$ & $\begin{array}{l}\text { MLP BPNN; } \\
\text { Support } \\
\text { Vector } \\
\text { Machine } \\
\text { (SVM) K- } \\
\text { NN }\end{array}$ & $\begin{array}{l}\text { The work is dependent on data classification concept. } \\
\text { Initially, a model/classifier has been depicted by means } \\
\text { of predefined classes, it is known as the training phase in } \\
\text { which the classification technique has developed the } \\
\text { classifier by learning from the dataset of training and } \\
\text { from its subsequent class label. } \\
\text { In the subsequent phase (testing phase) has estimated } \\
\text { accuracy for classification for the classification model by } \\
\text { utilizing the test set for the training dataset. } \\
\text { Pre-processing techniques such as data selection, data } \\
\text { cleaning and data transformation are proposed to the } \\
\text { unique data before the process of classification for the } \\
\text { improvement of classification method accuracy. }\end{array}$ \\
\hline $\begin{array}{l}\text { Mahyat } \\
\text { Shafapour } \\
\text { Tehrani et al, } \\
\text { (2013) [9] }\end{array}$ & $\begin{array}{l}\text { Support } \\
\text { Vector } \\
\text { Machines, } \\
\text { Decision } \\
\text { Trees }\end{array}$ & $\begin{array}{l}\text { The demonstration of varied methods with spectral as } \\
\text { well as spatial attributes for the extraction of LULC of } \\
\text { the inner-city area, soil, water bodies and different plants } \\
\text { has taken place. }\end{array}$ \\
\hline
\end{tabular}

The SPOT 5 images as of 2003 to 2010 have been taken for Malaysia and Selangor with the classification has been carried out using KNN, SVM and DT classifiers.

\section{Sunitha} Abburu and

Suresh Babu Golla (2015)

[10]

Roya Abedi et al,(2015)

[11]

Bashir

Ahmed

et al,(2015)

[12]

$\begin{array}{ll}\text { Anand } & \text { Feed- } \\ \text { Upadhyay } & \text { Forward } \\ \text { et } & \text { Neural } \\ \text { al,(2015)[13] } & \text { Network } \\ & \text { (FFNN) }\end{array}$

Nikita

Aggarwal

et al, (2016)

[14]
Back

Propagation

Neural

Network

(BPNN)

Classificatio satellite

image

classification

k-Nearest

Neighbour

k-NN)

Pixel-Based

Classificatio

$\mathrm{n}$ (PBC) and

Object-

Based

Classificatio

n (OBC)
A summary of automated satellite image classification methods has been provided with a comparison of different reviews.

An evaluation of performance with the varied datasets

has been provided with the different datasets.

The study has investigated the possibility of KNN technique for estimating major forest attributes like height, density, basal area, trees DBH and forest cover type on the basis of the existing field of forest inventory for having a more accurate classification.

$\mathrm{NN}$ has been utilized for solving more variety of tasks for solving ordinary rule-based programming with speech recognition and computer vision.

The processing node has received and calculates an input value set with transfers the sum via activation of the function for giving the node output value that develops one of the inputs towards processing node in the subsequent layer.

In classification, LISS-III satellite image, the varied bands are gathered and RGB has been generated.

FFNN and backpropagation of error have been designed with ANN toolbox.

The result has been calculated according to the kappa coefficient and the accuracy.

The study has focussed on classification approached on the basis of object-oriented and pixel oriented.
MLP BPNN Provides most accurate results with an accuracy of $89.3 \%$,

The classification accuracy came out to be higher for K-NN classifier of 90 and $91 \%$ for 2003 and 2010 correspondingly.

Kappa coefficient is 0.87 for the data Less accuracy of DT classifier has $68.06 \%$ accuracy with the kappa coefficient of 0.6 for 2010 .

SVM classification accuracy ranges from DT as well as object-oriented classifier $80.06 \%$ having Kappa coefficient for 0.75 in 2003 with the $78.15 \%$ has kappa coefficient for 0.72 in 2010.

The review assists the researchers with the selection of suitable satellite image classification technique or methods on the basis of requirements.

KNN provides accurate classification and feasible thematic maps

BPNN is self-adaptive dynamic system and best for the classification satellite images than other techniques

The classification accuracy of ANN decreases with the increase in the number of neurons.

OBC provides more Optimal and efficient Classification than PBC. Object-based has spectral, spatial and temporal properties that can be utilized for high resolution remotely sensed data for overcoming the pixelbased classification limitations on the basis of the spectral data value.

It has been concluded that classification of object-based technique is exact as compared to pixel-based classification. 
Table 5. A Glance at Existing Techniques (continue)

\begin{tabular}{|c|c|c|c|}
\hline $\begin{array}{c}\text { Author \& } \\
\text { year of study }\end{array}$ & $\begin{array}{c}\text { Method used } \\
\text { in study }\end{array}$ & Proposed work & Concluding Remarks \\
\hline $\begin{array}{l}\text { Gong Cheng } \\
\text { et al, (2017) } \\
{[17]}\end{array}$ & $\begin{array}{l}\text { Handcrafted- } \\
\text { Feature-Based } \\
\text { Methods, } \\
\text { Unsupervised } \\
\text { Feature } \\
\text { Learning- } \\
\text { Based } \\
\text { Methods, } \\
\text { Deep-Feature- } \\
\text { Learning- } \\
\text { Based } \\
\text { Methods }\end{array}$ & $\begin{array}{l}\text { Initially, an inclusive evaluation of current work of } \\
\text { remote sensing approaches has been given. } \\
\text { Dataset "NWPU-RESISC } 45 \text { " has been proposed that } \\
\text { consisted of } 31500 \text { images with fourty five scene } \\
\text { classes and seven hundred images in every class. } \\
\text { Different representative techniques have been executed } \\
\text { with the dataset. }\end{array}$ & $\begin{array}{l}\text { The research can help the researchers } \\
\text { to adopt more influential and multi- } \\
\text { view feature representation. }\end{array}$ \\
\hline
\end{tabular}

\section{EXISTING WORK ANALYSIS}

This section defines the work of Harish Kundra and Harsh Sadawarti [17] explaining the satellite image classification using nature-inspired classification algorithm, namely, PSO and Cuckoo Search. The authors have presented the hybridization of optimization algorithms such as PSO and Cuckoo Search to reduce the classification error rate and to improve the accuracy based on objective function. The Figure 3 displaying is a satellite image of Alwar region in India. This region is selected because it carries some superior land cover features like Urban, Barren, Water, Vegetation, and Rocky areas.

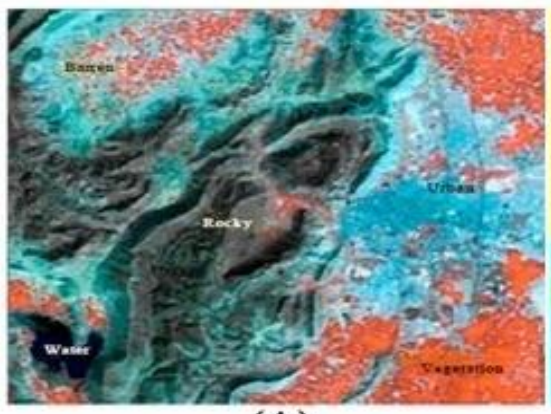

(A)

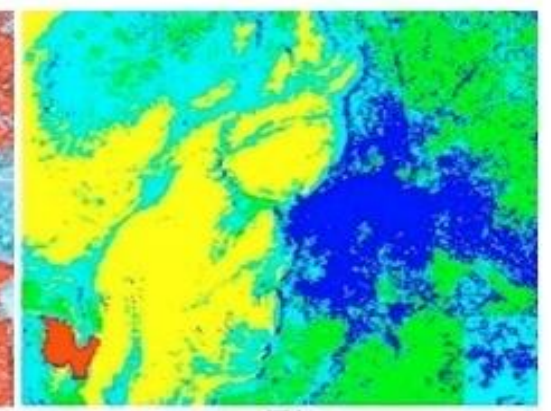

(B)

Figure 3. Comparison of the Original image (A) and classified image

(B) and Using satellite image classification 
The process of satellite image classification falls under two process namely training and classification. The training process is further categorized in preprocessing and optimization of the dataset.

\section{Algorithm 1. Data Preprocessing (Raw Data)}

1. For each d in the data row.Dataset(Raw_Data)

2. D1=Dataset(d).allcolumns(); // Taking all column data as input raw data, now it has to be decided that which

3. For each element in D1 data has to be used and which not

4. Population_Size=D1.element count

5. Apply optimal solution(D1)

6. Fit_Value $=[]$;

7. Count $=1$;

8. For each D1 element

9. CurrentElement=D1;

10. Threshold=lamda;

11. $\mathrm{L}=$ ApplyFitnes(Threshold,CurrentElement);

12. If $\mathrm{L}==1$

13. Fit_Value $(D 1$. Value, count $)=$ Current;

14. Count $=$ Count +1 ;

15. End

16. End Algorithm

Algorithm 1 describes the processing of raw data in which it utilizes a fitness function to drop or select data for processing. The selection of the threshold is done on the basis of the data passed to the optimization function. If the data satisfies the fitness function then it is selected else it is dropped. The selection of the fitness function is dependent on data set utilized. The training mechanism includes the utilization of training function which takes the optimized set as input and then trains the data according to the training structure. The structure of the training algorithm is as follows.

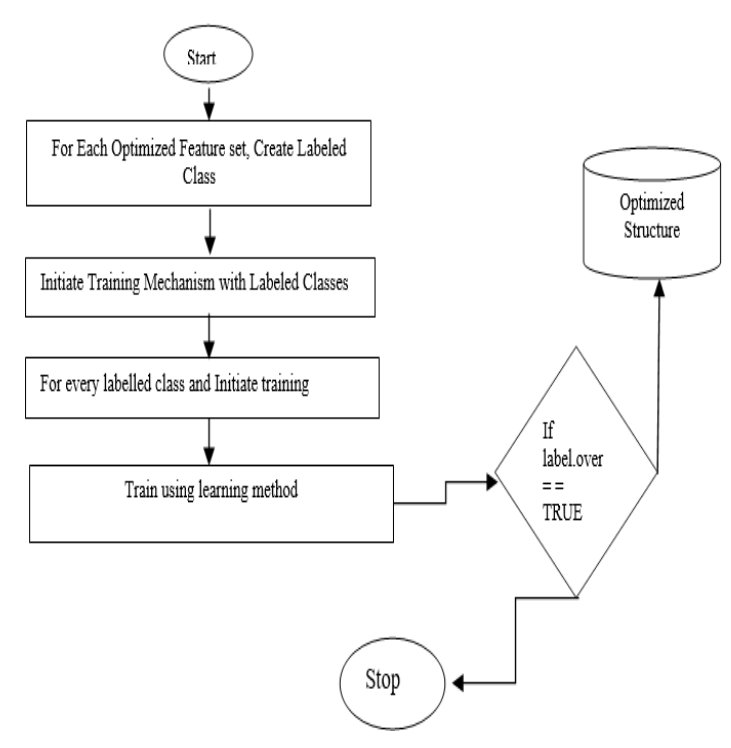

Figure 4. Training configuration for satellite image

The trained architecture set is then sent for the classification. The classification process is completely based on the ground truth values. The result will be the matched with the ground truth values. The classification algorithm is as follows.
Algorithm 2. Classification Struc
1. For $j=1$ :OptimizedStructure
2. Classified_Structure=Classify ( Optimized Structure, Ground_Truth_Value );
3. Df = Classified_Structure - Ground_Truth_Value;
4. End
5. For each df in Diff values // Taking the difference of the classified structure 
6. If $\mathrm{df}$ is not $==0 / /$ if the difference is not 0 it means that the ground truth value is not equal to the classified value,

7. False Classification++; // False classification rate in incremented

8. Else

9. TrueClassification++; // If the classified sample is true then true classification is incremented.

10. End

11. End

12. End Algorithm

The classification process takes the trained structure as input and plots the ground truth value against the trained structure to simulate. If the classified set is different from the ground truth value then the false classification is incremented else true classification is incremented.

\section{CONCLUSION}

This paper dealt with satellite image classification for classifying a satellite image and is dependent upon the feature extraction and classifiers. A concept of remote sensing is explained which is a technique used for gathering the information of the object on the earth surface. There are various remote sensing images types shown in tabular form in the manuscript. There are different types of image classification methods which are defined in the paper on the basis of criteria, characteristics and its examples. For finding the features in the bands, varied feature extraction techniques being used as the representation of the areas. After calculating the features of an image, classification methods are used to classify the regions present in the satellite image. The accuracy may deteriorate if the appropriate feature extraction and classification methods are not used. In this survey, SVM, K-nearest neighbor and ANN (Artificial neural network) are defined that are considered as best for enhancing the accuracy. A representation of satellite image classification is also shown that draws the comparison of the original image and classified image of Alwar Region. Future lies in the usage of a dataset of satellite image to achieve better accuracy and to minimize classification error rate.

\section{REFERENCES}

[1] Yongguan Xiao, Soo Kuan Lim, Tiow Seng Tan, and Seng ChuanTay, "Feature extraction using very highresolution satellite imagery," IEEE International Proceedings Geoscience and Remote Sensing Symposium, (IGARSS'04), vol. 3, 2004.

[2] GiorgosMountrakis, JunghoIm, and Caesar Ogole, "Support vector machines in remote sensing: A review," ISPRS Journal of Photogrammetry and Remote Sensing, vol. 66(3), pp. 247-259, 2011.

[3] Lu, Dengsheng, and Qihao Weng, "A survey of image classification methods and techniques for improving classification performance," International Journal of Remote sensing, vol. 28, issue 5, pp.823-870, 2007.

[4] Wilkinson, Graeme G, "Results and implications of a study of fifteen years of satellite image classification experiments," IEEE Transactions on Geoscience and remote sensing, vol. 43, no. 3, pp. 433-440, 2005.

[5] Manoj Pandya, AsthaBaxi, M.B. Potdar, M.H. Kalubarme, Bijendra Agarwal, "Comparison of Various Classification Techniques for Satellite Data," International Journal of Scientific \& Engineering Research, vol. 4, no. 1, 2013.

[6] Pushpendra Singh Sisodia, Vivekanand Tiwari and Anil Kumar, "A Comparative Analysis of Remote Sensing Image Classification Techniques," IEEE International Conference on Advances in Computing, Communications and Informatics (ICACCI), pp. 1418-1421, 2014.

[7] NurAnisMahmon and NorsuzilaYa'Acob, "A review on classification of satellite image using Artificial Neural Network (ANN)," IEEE 5 th Control and System Graduate Research Colloquium (ICSGRC), pp. 153-157, 2014.

[8] Soumadip Ghosh, Sushanta Biswas, Debasree Sarkar, and ParthaPratim Sarkar, "A tutorial on different classification techniques for remotely sensed imagery datasets," S, martCR, vol. 4(1), pp. 34-43, 2014.

[9] Mahyat Shafapour Tehrany, Biswajeet Pradhan, and Mustafa Neamah Jebuv, "A comparative assessment between object and pixel-based classification approaches for land use/land cover mapping using SPOT 5 imagery," Journal Geocarto International, vol. 29(4), pp. 351-369, 2014.

[10] SunithaAbburu, and Suresh BabuGolla, "Satellite image classification methods and techniques - A review," International journal of computer applications, vol. 119(8), 2015.

[11] Abedi, Roya, and Amir EslamBonyad, "Estimation and Mapping Forest Attributes Using K Nearest Neighbour Method on IRS-P6 LISS III Satellite Image Data," EcologiaBalkanica, vol. 7(1), 2015.

[12] Boshir Ahmed, and Md Abdullah Al Noman, "Land cover classification for satellite images based on normalization technique and Artificial Neural Network," In IEEE 1st International Conference on Computer and Information Engineering (ICCIE), pp. 138-141, 2015.

[13] Anand Upadhyay, S. K. Singh, Pooja Singh, and Priya Singh, "Comparative study of artificial neural network based classification of IRS LISS-III satellite images," In IEEE International Conference on Green Computing and Internet of Things (ICGCIoT), pp. 961-965, 2015. 
[14] Nikita Aggarwal, Mohitsrivastava, and Maitreyee Dutta, "Comparative Analysis of Pixel-Based and Object-Based Classification of High Resolution Remote Sensing Images - A Review," International Journal of Engineering Trends and Technology (IJETT), vol. 38(1), pp. 5-11, 2016.

[15] Sayali M. Jog, Mrudul Dixit, AnujaRajgopalan, and S. D. Ranade, "KNN and SVM based Satellite Image Classification," International Journal of Innovative Research in Electrical, Electronics, Instrumentation and Control Engineering, vol. 4, issue 6, pp. 158-162, 2016.

[16] KadirSabanci, M. FahriÜnlerşen, and Kemal Polat, "Classification of Different Forest Types with Machine Learning Algorithms," Research for Rural Development, vol. 1, 2016.

[17] Gong Cheng, Junwei Han, and Xiaoqiang Lu, "Remote Sensing Image Scene Classification: Benchmark and State of the Art," Proceedings of the IEEE, 2017.

[18] Harish Kundra and Harsh Sadawarti, "Hybrid Algorithm of Cuckoo Search and Particle Swarm Optimization for Natural Terrain Feature Extraction," Research journal of Information Technology, vol. 7, ssue 1, pp. 58-69, 2015.

\section{BIOGRAPHIES OF AUTHORS}

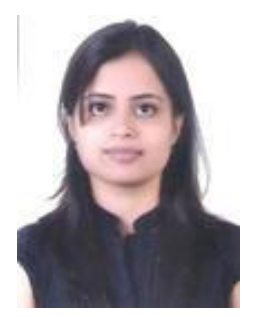

Sakshi Dhingra is an Assistant Professor in Department of Computer Science and Engineering in Guru Jambheshwar University of Science and Technology, Hissar, Haryana, India. She graduated from Punjab Technical University Jalandhar in 2010 and received Master's Degree (Gold Medallist) in Computer Science and Engineering from Guru Jambheshwar University of Science and Technology in 2012. She has presented many papers in International Journals/Conferences. She has supervised many students at M.Tech and MCA level. Her areas of interest are Image Processing, Soft Computing, and Remote Sensing.

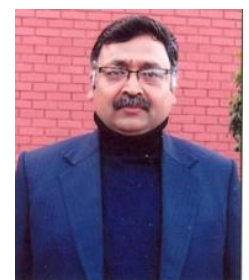

Prof. Dharminder Kumar is currently working as Professor in Computer Science and Engineering Department of Guru Jambheshwar University of Science and Technology, Hissar, Haryana, India. He is coordinator of Technical Education Quality Improvement Programme (TEQIP) of World Bank. He also worked as Dean of Faculty of Engineering and Technology, Head of Department (HOD) of Computer Science and Engineering and founder Dean of Colleges. He has supervised many students at PhD and M.Tech. Level. His area of interest includes Data Mining and Computer and communication Networks. 